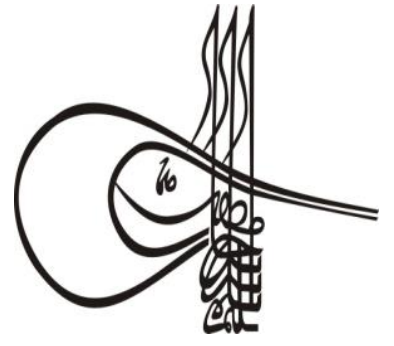

Turkigh Studies

CUDES 2019

Volume 14 Issue 5, 2019, p. 1-15

DOI: 10.29228/TurkishStudies.22986

ISSN: $1308-2140$

Skopje/MACEDONIA-Ankara/TURKEY

Research Article / Araştırma Makalesi

Article Info/Makale Bilgisi

Received/Geliș: 04.05.2019

$\checkmark$ Accepted/Kabul: 10.08.2019

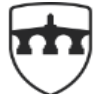

INTERNATIONAL BALKAN UNIVERSITY

EXCELLENCE FOR THE FUTUR IBU.EDU.MK

Report Dates/Rapor Tarihleri: Referee 1 (27.05.2019)-Referee 2 (29.05.2019)

This article was checked by iThenticate.

\title{
SAVAŞIN STRATEJİK PARÇASI ANLATI: AFGANISTAN ÖRNEĞİ
}

\author{
Kıvılcım ROMYA BILGIN*
}

\begin{abstract}
ÖZ
Anlatı, aktörlerin kendilerine ve başkalarına verdiği anlamlarla ilgili hikâye sistemleridir. Anlatılar her zaman savaşların bir parçası olmuştur. Anlatılar kısaca hikâye sistemleri olsalar da 20. yüzyılın son çeyreğinden bu yana değişen savaşlarda etki gücüne sahip yeni stratejik araçlar haline gelmişlerdir. Çünkü anlatılar etki yaratırlar ve bazen toplumları değişmeye zorlarlar. Bunu yapabildikleri zaman da stratejik değeri olan araçlar olurlar. Ancak bunun gerçekleşmesi için iki temel koşul yerine getirilmelidir. Öncelikle, savaşlardaki anlatının parçalarını oluşturan hikayeler birbirleri ile tutarlı olmalıdır. Bunun yanı sıra insanların sadece anlatılan hikayelerin dinleyicileri değil, aynı zamanda aktif birer katılımcı olma isteklerine cevap verilmelidir. Bu açıdan, görülmektedir ki savaş ile anlatı arasındaki ilişki oldukça karmaşıktır. Bununla birlikte savaşlarda devletlerin yanı sıra terör örgütleri ve kalkışmacı gruplar gibi yeni aktörler öne çıkmıştır. Bu yeni aktörler de devletler gibi kendilerine savaşlarda stratejik avantaj elde etme arayışındadır. Başka bir deyişle, anlat1, politik aktörlerin politik hedeflerine ulaşırken ihtiyaç duydukları stratejik avantaji elde etmeleri için bir kaynak haline gelmiştir. 2006'da ABD ordusunun Afganistan'daki komutanı General David Petraeus, basit, anlaşı1ır ancak yerel halkın sorularına cevap veren bir anlatı oluşturmaya çalışmıştır. Bu sayede ABD'ye Afganistan'da stratejik, operasyonel ve taktik pozisyonlarda avantaj sağlamayı amaçlamıştır. Öte yandan Taliban, ABD ve diğer NATO güçlerine karşı kendi anlatılarıyla sahada etkin olmaya çalışmıştır. Sonucunda Afganistan'daki savaş bir anlatı savaşı haline gelmiştir. Bu noktada Afganistan'daki savaşın tartışılması, anlatıya savaşlardaki değişen stratejik unsurlardan biri olarak bakılması açısından gereklidir. Çalışma kapsamında bu temel çerçeveden yola çıkılarak ABD'nin ve Taliban'ın anlatılarının güçlü ve
\end{abstract}


zayıf yanları ele alınacak ve Afganistan'daki savaş kapsamında anlatının stratejik değeri gösterilecektir.

Anahtar Kelimeler: Anlat1, Savaş, Afganistan, Strateji.

\title{
NARRATIVE AS THE STRATEGIC PART OF WAR: THE CASE OF AFGHANISTAN
}

\begin{abstract}
Narrative is story system about the meanings that actors give to themselves and others. However, the value of the narrative in the current wars has been strengthened. Although narratives are short story systems, they are the new strategic tools that have influence in the wars that have changed since the last quarter of the 20th century. Because narratives create effects on societies and sometimes force societies to change. When they do so, they become tools with strategic value. However, two basic conditions must be fulfilled for this to happen. First, the stories that consist of the narrative in the wars should be consistent with each other. In addition to this, people should not only be the listener of the stories told but also be an active participant of them. In this respect, it is seen that the relationship between war and narrative is quite complex. In the new wars, new actors such as terrorist organizations and insurgents stand out in addition to states. These new actors, like the states, seek to gain strategic advantage. In other words, the narrative becomes a resource for political actors to obtain the strategic advantage that they need to achieve their political goals. In 2006, General David Petraeus, the commander of the US military in Afghanistan, aimed to create a narrative that was simple, understandable, but answered the questions of the local people. In this way, he tried to give the US an advantage in strategic, operational and tactical positions in Afghanistan. and aimed to give the US an advantage in strategic, operational and tactical positions in Afghanistan. On the other hand, the Taliban tried to be active in the field of operations with their own narratives against the US and other NATO forces, as well. Therefore, the war in Afghanistan has become a narrative war. At this point, the discussion of the war in Afghanistan is necessary in terms of looking at the narrative as one of the changing strategic elements in wars. Within the scope of this study, the strong and weak aspects of USA and the Taliban narratives will be discussed and the strategic value of the narrative will be indicated in the Afghanistan war.
\end{abstract}

\section{STRUCTURED ABSTRACT}

Narratives are the new strategic tools, although they are short story systems that have influence in the wars that have changed since the last quarter of the 20th century. Because the narratives create effects on societies and sometimes force societies to change. When they can do so, they become tools with strategic value. However, to achieve this, narratives must fulfill two basic conditions. First, the stories that make up the parts of the narrative in the wars should be consistent with each 
other. In addition to this, people should not only be the listener of the stories told but also be an active participant of them. Actually, narratives are an essential part of strategic communication plans. Strategic communication takes its power from a complementary and consistent relationship between actions and stories being part of the narrative. Therefore, by linking appropriate narratives to actions, the integrity of action-discourse is ensured and the purpose of strategic communication is achieved.

The role of narrative in wars adds to the narrative a separate strategic value. In this context, it is possible to define the strategic narrative as a source used for shaping the public perceptions, beliefs, and behaviors and creating common meanings for political actors (Miskimmon, O'Loughlin \& Roselle 2013: 32). Thus, strategic narratives are a tool for political actors to expand their sphere of influence, to change expectations and to effect the environment they manage (Miskimmon, O'Loughlin \& Roselle 2013: 32). In this respect, it is seen that the relationship between war and narrative is quite complex. This complex relationship has shown itself in the conflicts between the US and the Taliban in the Afghanistan war. In recent years, the US has used the strategic narrative to legitimize the international, national and regional public opinion in the wars of Iraq and Afghanistan. Moreover, for NATO the strategic narrative has become a benchmark for the success of NATO's missions. However, it should be considered that strategic narrative is not only a tool of states and international organizations, but non-state actors such as Taliban and al-Qaeda try to provide local support to their actions through strategic narrative.

The US has begun to think about the narrative in wars with the experience it gained from the Vietnam war long before Iraq and Afghanistan. However, the strategic narrative gained importance with the intervention of Iraq and Afghanistan after 9/11. In the period 2001-2014, the US did not fight with Taliban only with military vehicles. Since the Taliban began to regroup and mobilize in 2003, the first thing Taliban did that in Afghanistan traditional and religious society in rural areas has been to develop narratives. The US and Afghan government have consistently failed to offer a reliable narrative resonating to the Afghan people. On the other hand, the Taliban produced powerful, simple and culturally meaningful narratives to control the Afghan people. Therefore, it would not be wrong to define the war of Afghanistan as a war of narratives (Johnson ve Steele, 2013: 71). In this study, the strengths and weaknesses of the narratives of the United States and Taliban were discussed in a comparative manner, and the strategic value of the narrative was tried to be shown in wars. The comparison in the study focuses on the period between 2001 and 2014 when the US began to interfere with Afghanistan and continued officially under the name NATO International Security Assistance Force (ISAF) operation. In the period of 2001-2014, most intense conflicts have happened between the parties.

The narratives of the US and the narrative of the Taliban have always been competitors. The US has sought to develop ties with Afghans by using narratives to provide the tactical advantage over the Taliban. The United States used narratives to seek intelligence from a village against the Taliban when necessary or, if necessary, to seek logistical assistance from the Afghan people. In this process, the US always had to

\section{Turkish Studies}

Volume 14 Issue 5, 2019 
struggle with the narrative of the Taliban and develop a counternarrative. Competing with the linguistic, cultural and religious advantages of the Taliban has been a challenge for the US.

In particular, due to the lack of attention to civilian casualties or religious sensitivities, the integrity of action-discourse has been impaired and the strategic advantage to be gained by narrative has been lost. NATO's multinational structure and military bureaucracy have also made it difficult to develop a common language that its narrative needs.

Taliban's narratives based on Afghanistan's history, culture and Islam have been very simple and understandable. This was the most important point that provided the strategic advantage of the Taliban's narrative. In addition to the advantages of the Taliban over language, religion, and culture, it has been advantageous of mixing with the local people and sometimes to share the same living spaces with them in order to disseminate and share the narrative. The Taliban has effectively used such instruments as poetry, tale and divine in Afghanistan where verbal culture has developed. On the other hand, the violence against the civilian population caused the people of Afghanistan, which the Taliban tried to win, to develop a reaction against it. It created a problem due to lack of integrity of action-discourse and created a strategic disadvantage in the narrative.

At the international, national and regional level, public opinion through war narratives form an explanation framework for understanding wars. This opens the way for the governments to take what they want from the people they govern at the time of the war. At the same time, it provides operational and tactical advantages in the field of intelligence, logistics or operations against enemy elements in the field of operation. In this respect, narratives are effective in long, medium and short term as well as international, national and regional level. As a result of this framework, the role of strategic narrative in wars is inevitable.

Keywords: Narrative, War, Afghanistan, Strategy.

\section{Giriş}

Savaşlar, günümüzde devletlerarası bir olgu olmasının ötesinde çok aktörlü, değişkenli ve katmanlı her zamankinden daha karmaşık olgular haline gelmişlerdir. Bunun neticesinde, savaşlarda taraflar için stratejik, operasyonel ya da taktiksel avantaj elde edebilmek için yeni kavramlarla düşünmek bir zorunluluktur. Anlatı ise bu kavramlardan sadece biridir. Anlatının, savaşan taraf ister devlet ister terör örgütü ve kalkışmacı grup gibi savaşların yeni aktörleri olsun savaşlarda istenilen başarının elde edilmesinde dikkate alınması gerekmektedir. Çünkü savaşlarda anlatılar, insanların olayları bir çerçeveye koymalarını ve ihtiyaç duydukları cevapları almalarını sağlar. İnsanlara askeri gücün kullanımını anlamaları için gereken çerçeveyi vererek ve onları hikayelerin bir parçası yapar. Ancak etkili olmaları için genellikle değerlere, ilgi alanlarına ve önyargılara ihtiyaçları vardır (Bilgin, 2018: 240-241). Dolayısıyla çatışmalarda stratejik anlatı her zamankinden daha değerli bir stratejik araç haline dönmüştür.

ABD, Irak ve Afganistan'dan çok daha önce Vietnam savaşı sonucunda edindiği tecrübe ile savaşlarda anlatı üzerine düşünmeye başlamıştır. Özellikle stratejik niteliği ile anlatı 11 Eylül saldırıları sonrasındaki Irak ve Afganistan müdahaleleri ile önem kazanmıştır. İngiltere'nin 1948-1960 yılları arasındaki Malaya tecrübesi sonucunda ortaya çıkan 'kalpleri ve akılları kazanmak' stratejisi tekrar 
gündeme gelmiştir. Bu kapsamda, ABD, özellikle Afganistan Savaşı'nın 2001-2014 yılları arasındaki döneminde hem kendi kamuoyu nezdinde hem yerel halk nezdinde hem de uluslararası kamuoyu nezdinde meşruluk kazanmak için anlatıyı sistemli bir şekilde geliştirme ihtiyacında olmuştur. 2006 y1lında ABD'nin Afganistan'daki birliklerinin komutanı General David Petraeus'un öncülüğünde kalkışma ile mücadele (counterinsurgency) ${ }^{1}$ stratejisine ilişkin yazılan doktrinde, kalkışma ile mücadelede basit, anlaşılır ancak yerel halkın sorularına yanıt verecek bir anlatı oluşturulmasının (USACAC, 2006) vurgulanması ile anlatı stratejik yönü ile ABD'nin Afganistan'daki operasyonlarında önemli bir unsur haline gelmiştir. Ancak bundan çok daha önce ABD, kendi kamuoyu nezdinde stratejik anlatıyı kitle iletişim araçları aracılığı ile yoğun bir şekilde kullanmıştır. 11 Eylül saldırıları ve saldırılar sonrası 'terörle küresel savaş' sloganı stratejik anlatısının temel unsurları olmuştur (Bilgin, 2018: 240241). Bunu yaparken ABD, Afgan halkının desteğini kazanabilmek için savaşmak istemediği ancak teröristlerin ABD’yi buna mecbur bıraktı̆̆ı mesajını vermeye de özen göstermiştir.

Aslında Afganistan'da savaş her zaman bir anlatı savaşı olmuştur (Johnson ve Steele, 2013: 71). Çünkü ABD, Afganistan'daki operasyonlarını yoğun olarak sürdürdüğü 2001-2014 döneminde Taliban ile sadece askeri olarak mücadele etmemiştir. Taliban'ın 2003 yılı itibarıla tekrar güç toplamaya başlaması ve kalkışma hareketinin ivme kazanması ile birlikte Afganistan'ın kırsal kesimlerindeki geleneksel ve dindar topluma karşı ilk yaptığı şey anlatılar geliştirmek olmuştur. Bu süreç içerisinde ise $A B D$ ve Afgan hükümeti, Afgan halkını rezonans eden güvenilir bir anlatı sunma konusunda sürekli olarak başarısız olmuştur. Öte yandan, Taliban, Afgan halkını kontrol etmek için güçlü, basit ve kültürel anlamda anlamlı anlatılar üretmiştir. Bu çalışma kapsamında, ABD ve Taliban'ın anlatılarının güçlü ve zayıf yanları karşılaştırmalı bir şekilde ele alınarak, savaşlarda anlatının stratejik değeri gösterilmeye çalışılacaktır. Karşılaştırmada ABD'nin Afganistan'a müdahalesi ile başlayan ve resmi olarak NATO'nun Uluslararası Güvenlik ve Yardım Operasyonu (International Security Assistance Force$I S A F$ ) operasyonunun sonlandırıldığı aynı zamanda da taraflar arasında sıcak çatışmalarının en yoğun olduğu 2001-2014 yılları arasındaki dönemde Afgan halkına yönelik geliştirilen anlatılara odaklanilacaktır.

\section{Anlatının Kavramsal Çerçevesi ve Stratejik Önemi}

Anlatının ne olduğu ve nasıl kullanıldığı konusunda görüş birliği çok azdır. Ancak bu durum anlatı üzerine bir tartışma yürütülmesine ve anlatının anlaşılmasına engel teşkil etmemektedir. Anlatı farklı disiplinlerden gelen kişiler için farklı yönleri ön plana çıkarılarak tanımlanmaktadır. Stratejik iletişim alanındaki çalışmaları ile tanınan Corman, anlatıyı ortak temaları, formları ve örnekleri olan bir hikâye sistemi olarak tanımlamaktadır (2011: 36). Askeri konularda uzman olan Kilcullen ise anlatıyı, insanların tecrübelerini organize ederek olayları anlamaları için onlara bir çerçeve sunan basit hikâye ya da açıklama olarak tanımaktadır (2007). Nissen'e göre anlatı, çatışmaya neden olan temel motivasyonun ortadan kaldırılmasına yönelik ortak temalara, olaylara, biçimlere ve kişilere dayalı geliştirilen hikâye sistemidir (2014: 157). Anlatıya ilişkin tanımlamaları artırmak mümkündür ancak tanımların her biri üzerinde ayrıca durmaktan ziyade anlatının ne olduğuna ilişkin yürütülen tartışmalar çerçevesinde anlatından ne anlaşılması gerektiği anlaşılmalı bu yapılırken öncelikle stratejik iletişimin çerçevesinin ne olduğu ortaya konulmalıdır.

\footnotetext{
${ }^{1}$ Çalışmada, counterinsurgency kavramı Türkçeleştirilirken kalkışma ile mücadele kavramı kullanılmıştır. Bununla birlikte counterinsurgency kavramına karşı1ık direnişle mücadele ifadesinin de kullanılması da mümkündür. ABD'nin sınırları ötesinde gerçekleştirdiği operasyonlarda, operasyonun stratejik, operasyonel ya da taktik hedeflerine karşı çıkan grupları "resistance" ile ifade ederek counterinsurgents gruplar içerisinde ayrı bir tanımlama oluşturmasından ötürü ABD'nin veya İngiltere'nin counterinsurgency operasyonları ele alınırken direnişle mücadele ifadesinin kullanılmasının da uygun düşeceği değerlendirilmektedir. Bknz. US Army and Marine Corps. Counterinsurgency Field Manual 3-24, 2007 ve British Army. Field Manual Volume 1 Part 10 Countering Insurgency, 2009.
} 
Bunun nedeni ise anlatıların esasında stratejik iletişim planlarının önemli birer parçası olmalarıdır. Bu nedenle anlatıyı anlamak için stratejik iletişimin ne olduğuna kısaca bakmak gerekmektedir. Stratejik iletişim, uyum içinde çalan bir orkestra gibidir. Bu orkestrayı düşündüğümüzde orkestra şefi 'devlet'tir. Müzik notlarının dizeği stratejik iletişim planı, orkestra üyeleri çeşitli uygulayıcı kurum ve kuruluşlardır. Müzik ise stratejik iletişim kullanılan hikâye sistemi yani anlatıdır (Güler, 2018: 128-129). Dolayısıyla, anlatının olmadığı bir stratejik iletişim planlaması ve süreci düşünülemez. Stratejik iletişim gücünü anlatının parçası olan hikayeler ile eylemler arasındaki tamamlayıcı ve tutarlı ilişkiden alır. $\mathrm{Bu}$ nedenle, uygun anlatıların eylemlerle ilişkilenmesiyle eylem-söylem bütünlüğü sağlanır ve eylem-söylem bütünlüğü ile stratejik iletişim amacına ulaşır. Bu noktadan hareketle anlatı ele alındığında anlatıya ilişkin tüm tanımlardaki anlatının bir iletişim sürecini anlamlı hale getiren bir hikâye sistemi olduğuna ilişkin ortak noktaya kendiliğinden ulaşılmış olur. Neticede anlatı, aktörlerin kendilerine ve başkalarına verdikleri anlam ile ilgilidir. Ancak esas mesele bu anlamının ötesinde, anlam verme çabasının altında yatan niyettir. Bu niyetin varlı̆̆g ile elde edilmek istenilen amaç anlatıya işlevsel bir boyut kazandırır. Anlatının, strateji ile olan ilişkisi de kendini tam da bu noktada gösterir. Öncelikle stratejik anlatılara ilişkin literatürde yer alan tartışmalar uluslararası ilişkilerdeki konstrüktivizmin etkisinde geliştiği belirtilmelidir. Güç ilişkilerinin, fikirler ve kültürel kodlarla inşa edildiği fikrinden yola çıkarak temellenen konstrüktivizm (Wendt, 1992), uluslararası ilişkilerde aktörlerin kimlik ve davranışlarının inşasında anlatıya önem vermesi ile stratejik anlatıyı özellikle gündeme getirir (Miskimmon, O’Loughlin \& Roselle 2013: 32).

Günümüzde çatışmalarda stratejik anlatı her zamankinden daha değerli bir stratejik araç haline gelmektedir. $\mathrm{Bu}$ çerçevede stratejik anlatıyı, siyasal aktörler için kamuoyunun algı, inanç ve davranışlarını şekillendirmek ve ortak anlamlar yaratmak amacıyla kullanılan bir kaynak olarak ele almak mümkündür. Dolayısıyla stratejik anlatılar, siyasal aktörler için etki alanlarını genişlettikleri, beklentileri yönettikleri ve yönettikleri çevreyi değiştirmek için kullandıkları bir araçtır (Miskimmon, O’Loughlin \& Roselle 2013: 32). Stratejik anlatı, stratejik konuların daha kişisel ve anlamlı yolla anlatılmasına imkân vermesi sayesinde bir araç olarak işlev kazanır (Dimitriu \& Graff, 2016: 6). Bu kapsamda, hükümetlerin askeri iletişim stratejilerini stratejik anlatı ile şekillendirdikleri görülmektedir. Çünkü stratejik anlatı olayları ikna edici bir şekilde açıklamayı sağlar. Anlatılan hikâyeler olayları bir çerçeveye oturtmaya imkân verir ve olası cevapları karşılar. Etkili olabilmek için değerleri, çıkarları ve ön yargılara ihtiyaç duyar, onları kullanır (Bilgin, 2018: 240-241). İnsanlara askeri gücün kullanılmasını anlayabilmeleri ihtiyaç duydukları çerçeveyi verir (Freedman, 2006; Ringsmose \& Børgesen, 2011). Bu temelde iyi bir anlatı, sorunu, mağdur ve çözümü tanımlayan basit bir hikâye ile başlar (Zaharna, 2010: 109). Burada dikkat edilmesi gereken anlatı ile hedeflenen kitlenin kimlerden oluştuğudur. Bu nokta tam da uluslararası sistemde konstrüktivizm çizdiği çerçeveye uygun bir anlayış ile anlatının rolünün anlaşılması gerektiğini ortaya koyar. Çünkü anlatı, hedef kitleyi tanımlayan kültür, kimlik ve düşüncelerle ilişki içindedir. Bu nedenledir ki anlatılar sadece savaşan tarafların kendi toplumlarını savaşın gerekliliğine ikna etmeye yönelik geliştirilmemektedir. Anlatılar, savaşan taraflar için aynı zamanda potansiyel düşman olarak olabilecek yerel halklarının tutumlarını lehte etkilemek için de kullanılmaktadır. Bu nedenle, anlatının hedef kitlelere yönelik kapsamlı bir anlayış ile geliştirilmemesi stratejik niteliğini zayıflatabilir.

Kaldı ki savaş zamanı anlatı bir hikâye ya da Corman'ın vurgusu ile bir hikâye gurubundan fazlası (2011: 36) haline kaçınılmaz olarak gelir. Çünkü her ne kadar anlatı süslü ve edebi bir dünya ile ilgili gelse de aslında stratejinin bir parçasıdır hatta bazı durumlarda stratejinin esas kaynağıdır. Çünkü politika, retorik ve eylem savaşlarda artık daha fazla anlatı üzerine inşa edilmeye başlanmıştır. Bundan ötürü de savaşları anlamaya çalışırken savaşın bir parçası haline gelen stratejik anlatıyı anlamak bir gerekliliktir. Eğer anlatı askeri operasyonlara başarılı bir şekilde entegre edilecekse, anlatı gelişiminin ilkelerini anlamaya daha fazla özen gösterilmelidir. Stratejik (ana seviye) anlatı, operasyonel (yerel) seviyeye ve nihayetinde karadaki askerin günlük olarak yerel nüfusla etkileşime girdiği taktik seviyeye 
kadar akmalıdır (Shaikh ve Payne, 2014: 4). Bu akış, anlatıya tutarlılık, tutarlılık ise güç katacaktır. Bununla birlikte Vlahos, savaşlarda stratejik anlatının üç temel işleve sahip olması gerektiğini ifade eder. İlki insanları birbirlerine bağlayan ve kolaylıkla kabul edecekleri gerçeklere dayanarak oluşturulan politikanın çerçevesini organize etmelidir. İkincisi stratejik anlatının iddia ettiği gerçekler kültürel olarak sökülmeye ve hatta eleştirilmeye açık olmamalıdır. Son olarak anlatı pratik olarak savaşın nasıl savunulacağı ve anlatılacağına dair kutsal bir retorik el kitabına görevini yerine getirmelidir (2006).

Savaş özelinde anlatıya kazandırılan bu stratejik işlev, stratejik anlatının iktidarlar tarafından nasıl bir meşruiyet aracı haline getirildiği üzerinde düşünmeye zorlamaktadır. Çünkü stratejik anlatı hükümetlere savaş zamanı yönettikleri insanlardan istediklerini alabilmeleri için gerekli yolu açar (Vlahos, 2006). Stratejik anlatı, siyasal aktörlere dünya düzenini beklentilerine göre yönetebilmeleri ve çevreyi değiştirebilmeleri için çıkarlarını, değerlerini ve arzularını ön plana çıkarmalarını sağlayan bir araçtır. Diğer bir ifade ile stratejik anlatı, siyasi aktörlerin, siyasal amaçlarına ulaşırken ihtiyaç duydukları meşruiyeti elde etmelerinde bir kaynak haline gelir. Bu durum savaş başlamadan önce kamuoyunun desteğinin sağlanmasında değil, kamuoyunun savaşın başlamasına olan desteği ile savaşın sürdürülmesine ilişkin desteği arasında yaşanan can kayıpları, mali kayıplar ve elitlerin savaşa konusundaki tutumlarından kaynaklı birtakım farkların yönetilmesinde de bir ihtiyaç olarak siyasal aktörün önüne çıkabilir. Esasında tüm bu tartışmalar stratejik anlatının savaşın meşrulaştırılmasında kullanıldığı tartışmasını doğal olarak yol açmaktadır. Mesele savaş yapmayı suç olarak gören Tilly’nin (1985) perspektifinden ele alındığında stratejik anlatının savaşın meşrulaştırılmasına kullanılması stratejik anlatıyı suç aleti olarak yorumlanmasına kadar varabilecek kadar uç bir noktadan stratejik anlatı meşruiyet arasındaki ilişkisinin yorumlanmasına imkân vermektedir.

Graaf ve diğerleri anlatı ile kamuoyu arasındaki ilişkinin kurcalanmasına yönelik sorular sorar. Öncelikle batılı hükümetler, bir seçim olarak algılanan yüksek maliyetli askeri müdahaleler için kamu desteğini inşa etmeye ve sürdürmeye nasıl çalışıyorlar? Bu amaçla ne tür argümanlar ve yorumlayıcı çerçeveler kullanıyorlar? Halk, seçkin askeri müdahaleler için popüler destek oluşturma çabalarına nasıl cevap veriyor? Dikkatle tasarlanmış metinler kullanarak halkın savaş algılarını gerçekte ne ölçüde etkilenebiliyor? (2015: 1-2). Bu soruları Graaf ve diğerleri anlatının savaşlardaki rolü ele alınırken sorulması ve cevaplanması gereken esas sorular olarak görür ve anlatı ile kamuoyu arasındaki tartışmanın eksenin bu sorulara verilecek cevaplar olacağını değerlendirir.

Son yıllarda ABD'nin, Irak ve Afganistan savaşlarında uluslararası, ulusal ve bölgesel kamuoyları nezdinde meşruiyet sağlamak için stratejik anlatıyı kullanması ve NATO'nun stratejik anlatıyı misyonların başarısı için bir ölçüt haline getirmesi stratejik anlatı konusunun ne kadar önemsendiği hakkında fikri vermektedir. Ancak stratejik anlatının sadece devletlerin ve uluslararası örgütlerin bir aracı olmadığı, Taliban ve El-Kaide gibi devlet dışı aktörlerin de stratejik anlatı üzerinden eylemlerine yerel destek sağlamaya çalıştıkları ve stratejik anlatıyı örgütlere katılım için araçsallaştırmaları da atlanmamalıdır. Bu noktadan hareketle ABD'nin ve Taliban'ın stratejik anlatıyı Afganistan'da operasyon sahasında nasıl kullanıldığına bakmak, stratejik anlatı tartışmalarını pratikte görmek açısından fayda sağlayacaktır.

\section{ABD'nin Stratejik Anlatısı}

ABD'nin Afganistan'a müdahale ettiği 2001 yılının sonundan ISAF operasyonun sonlandırıldığ 12014 yılının sonuna kadar geçen süre içerisinde başta askeri ve siyasi olarak bölgede attığı adımları Amerikan kamuoyuna, Afgan halkına ve uluslararası kamuoyuna açıklaması beklenmiş̧ir. ABD kimi zaman farklı kitlelerden gelen bu beklentileri karşılasa da kimi zaman bu beklentileri görmezden gelerek herhangi bir açıklama yapmadan bölgedeki askeri ve siyasi hedeflerini gerçekleştirmeye odaklanmıştır. Buna rağmen, $\mathrm{ABD}$ bu süreç içerisinde iletişimsel eksiklerinin farkına vararak stratejik hedeflerini gerçekleştirmek ve operasyonel ya da tatktik seviyede başarıyı artırmak amacıyla kapsamlı bir stratejik iletişim konsepti geliştirmeye yönelmiştir. Bu çerçevede, ABD 
hükümeti, ABD kamuoyuna, Afgan halkına ve uluslararası kamuoyuna iki sorunun cevabını vermeye yönelik anlatılar geliştirmiş̧ir: Neden Afganistan'a geldiler? Ne yapmaya çalışıyorlar? Zamanla bu iki soruya bir üçüncüsü eklenmiştir: Neden halen gitmediler?

$\mathrm{Bu}$ sorulara cevap vermek için stratejik iletişimin kullanılması ihtiyacı zaman içerisinde gelişmiştir. Bu çerçevede ABD'nin Afganistan'da stratejik iletişim konseptini ve buna bağlı olarak anlatısını geliştirme sürecini dört dönemde incelemek mümkündür. İlk dönem 2001-2003 arasıdır. Bu dönemde, Afganistan'daki operasyon ABD için hala terörle mücadele operasyonuydu ve iletişim operasyon sürecinde fazla dikkate alınmamakla birlikte var olan iletişimin de tek muhatabı doğrudan karşıdaki rakipti. Afganistan'daki çatışmalarda ABD istediği stratejik başarıyı elde edemeyince ve NATO operasyonu olarak ISAF'ın devreye girmesiyle 2003-2006 arasındaki geçiş dönemi başladı. Bu dönemde Taliban'ın güçlenmesi ile birlikte yavaş yavaş başarının anahtarının halk desteğinde olduğu anlaşıldı. Dolayısıyla iletişimin muhatabı olarak sadece rakibin görülmesinin yetersizliği daha net bir şekilde ortaya çıktı. 2006-2010 döneminde, kalkışma mücadele operasyonları ve artan şiddet ile birlikte bölgesel bir yaklaşıma daha fazla önem verilmeye başlandı (Dimitriu, 2012: 197). 2010-2014 arası dönemde ise ABD'nin Afganistan'dan büyük birlikleri ile çekilme hazırlıkları yaptığı ve ISAF operasyonunun kapatılarak daha küçük bir NATO misyonuna hazırlık yapıldığı dönem olmuştur. Bu dönemde ayrıca Afgan hükümetinin ülkede güvenliğin sağlanması başta olmak üzere diğer pek çok konuda daha güçlü inisiyatif almaya hazırlandığı dönemdir. Bu dönemde, ABD’nin çekilmesinin ne anlama geldiği ve çekilme sonrası sürecin nasıl olacağına ilişkin sorulara cevap verilmesi beklenmiştir.

İlk döneme etki eden anlatı eski ABD Başkanı G.W. Bush'un 11 Eylül saldırılarını gerçekleştirenlerden hesap sorulması için ortaya koyduğu 'teröre karşı savaş' anlatısı olmuştur. Bu anlatı askeri araçların kaçınılmaz olarak kullanılacağını, dolayısıyla şiddetin kaçınılmaz olacağına işaret etmekteydi. Ayrıca ABD'nin ne yapılması gerekiyorsa yapacağını, çünkü saldırılarda ölenler için intikam alma amacında olduğunu göstermekteydi. Nitekim bu anlatının kurucusu Bush'un sadece basın açıklamaları bile anlatıdaki intikam mesajını açıkça ortaya koymaktaydı (White House, 2019). Nitekim, $\mathrm{ABD}$ basınında da saldırıdan kısa süre sonra ortaya çıkan bu anlatıyı destekleyen haberleştirme süreçleri yaşanmıştır (Ryan, 2004). Öte yandan bu anlatının hedef kitlesi ABD ve uluslararası kamuoyuydu. Afgan halkına ilişkin bu anlatının kapsayıcılığı, özellikle ABD'nin neden Afganistan'a müdahalede bulunduğunu anlatmaktan çok uzaktı. Bu anlatının stratejik iletişim çerçevesinde planlı bir yaklaşımın sonucu olduğunu söylenemez. Ancak ABD, 2003 yılında Taliban'ın tekrar canlanması ve 2006 yılına kadar geçen sürede küçük çaplı da olsa kalkışma eylemlerine girişerek etki alanının genişletmesi ABD’nin Afganistan'a ilişkin stratejisini tekrar gözden geçirmesine neden olmuştur.

2006 yllına gelindiğinde ISAF ve ABD birliklerinin komutanı Orgeneral David Petraeus'un gözetiminde hazırlanan ABD Ordusu ve Deniz Piyade Birliği Kalkışma ile Mücadele Sahra Talimnamesi (FM 3-24 US Army and Marine Corps Counterinsurgency) iletişimin önemine vurgusu ve özellikle anlatı konusundaki kapsamlı yaklaşımı ile ABD açısından Afganistan'da bir değişim başlatmıştır. Bu dönemden sonra ABD'nin Afganistan'da stratejik anlatıyı kullanırken iki temel amacı olmuştur. Bunlardan ilki yerel düzeyde Taliban'a yönelik yürüttüğü operasyonlarda halk desteği sağlamak; ikincisi ise Taliban'ın stratejik anlatısı ile mücadele etmektir. Bunu yaparken de yöntem olarak yazılı iletişimden ziyade sözlü iletişime ağılık vermeye çalışmıştır. Bunun nedenlerini Afganistan'da okuma yazma oranlarının düşük olmasının² yanı sıra kültürel ve tarihsel olarak sözlü kültürün geliştiği bölgede sözlü iletişimin her zaman yazılı iletişimden çok daha güçlü olması şeklinde değerlendirmek mümkündür.

\footnotetext{
${ }^{2}$ Afganistan dünyada okuma yazma oranlarının en düşük olduğu ülkelerden biridir. UNESCO verilerine göre 15 yaş üstü yetişkin nüfusun okuma yazma oran $1 \% 31$ 'dir. Kadınlarda bu oran \%17, erkeklerde ise bu oran ortalama \% 45 'dir. Bknz. UNESCO Office in Kabul (2019). http://www.unesco.org/new/en/kabul/education/youth-and-adult-education/enhancementof-literacy-in-afghanistan-iii/.
} 
Bu kapsamda, ABD’nin operasyon sahasındaki komutanları ve diplomatları merkezi yönetim ve politikacılarla görüşmenin yanı sıra yerel liderler ya da kanaat önderleri ile de bir araya gelmiştir. ABD'nin Afgan halkının düşmanı olmadığı, asıl düşmanın Taliban'ın olduğu, ABD'ye destek vermeleri halinde Afgan halkının içine yerleşmiş bu ortak düşmandan birlikte kurtulabilecekleri mesajının güçlendirilmesi için çalışılmıştır. ABD'nin Afganistan topraklarında yürüttüğü operasyondan Taliban'ın yaptıklarını sorumlu tutan bir dil kullanılmıştır. ABD'nin 11 Eylül saldırılarının intikamını aldıktan sonra bölgeyi Afganistan hükümetine yani Afgan halkına bırakacağı, Afganistan'ı işgal etmek gibi bir niyetin olmadığı mesajı verilmeye çalışılmıştır. Bu çerçevede, ABD'nin bu dönemdeki anlatısı 'onur, intikam ve çıkış' şeklinde özetlenebilir (Tatham, 2009). Taliban'ın Afgan halkına verdiği zarar ve halkın en azından belirli bir kısmının Taliban'a karşı duyduğu hoşnutsuzluğu avantaja çevirebilmiştir. Taliban'ın etkisiz hale gelmesi ile ABD'nin Afganistan'dan gideceğini vurgulamıştır. ABD, bunu yaparken kadınlardan uzak durulması gibi kültürel hassasiyetlere önem vermeye çalışılmış ve 'namus' gibi Afgan halkı için önemli olan kültürel durumlara ve kelimelere referans vermeye özen göstermiştir. USAID $^{3}$ başta olmak üzere ülkede faaliyet gösteren uluslararası ya da yerel sivil toplum örgütleri aracılığıyla gıda ve tıbbi yardımlar başta olmak üzere bölge halkının ihtiyaçlarının karşılanmasına yönelik çabalarla stratejik anlatının güçlendirilmesi üzerinde durulmuştur.

Tüm çabalara rağmen ABD, stratejik iletişimin başarılı olabilmesi için temel şartlardan olan anlatıyı güçlendiren eylem-söylem bütünlügünü operasyon sahasında sağlayamamıştır. Bunun nedeni ise stratejik seviyede ortaya konulan anlatının taktik seviyede uygulanmasında zorlanılmasıdır. $\mathrm{Bu}$ durum, ABD'nin anlatısını zayıflatmanın yanı sıra operasyonlarda etkinliğine zarar vermiştir. Eylemsöylem bütünlüğünün bozarak ABD'nin anlatı ile elde etmeye çalıştığı stratejik avantajı en çok ortadan kaldıran unsur ikincil hasar (collateral damage) olarak adlandırdığı operasyonlardaki sivil kayıplardır. Operasyonlar neticesinde sivil halkın zarar görmesi ABD'nin sadece Taliban'ı hedef aldığına ilişkin söylemleriyle tutarsızlık oluşturmuş ve anlatısına zarar vermiş̧tir. Bunun yanı sıra, ABD prensipte her ne kadar yerel kadınlarla temastan kaçınılması gibi kültürel hassasiyetlere önem vermeye çalışmışsa da güvenlik gerekçesi ise kadınların Amerikan askerleri tarafından aranması gibi dini ve kültürel sebeplerle Afgan halkının tepki göstereceği pek çok olay yaşanmıştır. Yine camilerin güvenlik gerekçesi ile aranması veya ruhani liderlerin tutuklanması gibi olaylar (Burget, 2013: 88-89) ABD açısından anlatının eylem-söylem bütünlüğünden aldığı gücü ortadan kaldırmıştır. Dolayısıyla bunlar hem ABD'ye karşı oluşan toplumsal tepkinin hem de Taliban'a karşı gelişen sempatinin nedenlerini oluşturmuşlardır.

ISAF operasyonunun tüm aşamalarında askeri ağırlık ABD’lilerin elinde olmasına karşın, ABD'nin anlatısını geliştirirken ve yayarken yaşadığı zorluklardan biri de SAF Operasyonuna katkı sağlayan bazı ülkelerin kendi anlatıları ile operasyon sorumluluk sahalarında hareket etmeleri olmuştur. Ayrıca NATO üyesi olmayan ama operasyona katkı sağlayan Avusturalya gibi ülkelerin operasyonda yer alarak gösterdikleri fedakarlıklara odaklı anlatıları (Scheffer, 2015: XXV) meseleye eklendiğinde tutarlı ve kapsayıcı bir anlatı oluşturmak çok daha zor olmuştur. Çünkü ABD'nin tüm NATO üyelerini de kapsayıcı bir anlatı da geliştirmesi gerekmekteydi. Dolayısıyla ISAF operasyonunun çok uluslu yapısı ve NATO'nun karmaşık bürokrasisi içerisinde ABD'nin yaşadığı en büyük zorluk anlatısını tek bir ağızdan, tutarlı şekilde, aşağıdan yukarıya tüm yapılar tarafından benimsenerek uzun süreli sahiplenilmesini sağlamak olmuştur. ABD'nin özellikle Afgan halkı üzerinde yarattığı etkiye dayalı olarak anlatı ile elde ettiği ya da edemediği stratejik, operasyonel ya da taktik üstünlük sadece kendisini değil, ISAF operasyonu süresince ABD'nin müttefiklerini de bağlayıcı nitelikte olmuştur.

Anlatının insanlar arasında yayılmasını sağlamak için doğru yöntemlerin kullanılması da anlatıların doğru kurgulanması kadar önemlidir. Teknolojik olarak Afganistan'da radyo ve cep telefonları temel kitle iletişim araçlarıdır. Radyo kanallarının önemli bir kısmı ABD, İngiltere, NATO/ISAF ve BM tarafından kurulmuş olmasına karşın, Taliban da radyo istasyonları kurmuştur.

${ }^{3}$ USAID yardım programı için bknz. https://www.usaid.gov/ 
Taliban ile sınırlı da olsa radyo üzerinden sahada olduğu gibi bir rekabet ortamı oluşmuştur. Buna karşın, televizyona ya da bilgisayara sahip Afganlıların sayısı son derece sınırlı kalmıştır (Williston, 2015: 1314). Dolayısıyla ABD, en güçlü olarak kullanabileceği bu teknolojik alanı etkin olarak kullanmaktan mahrum kalmıştır. Öte yandan, ABD tüm medya araçlarını kullanırken, esas ihtiyacı olan yüz yüze iletişimde dil, kültür, ön yarg1 ve güvenlik nedeni ile istediği kadar etkin olamamış, bu konuda avantajı Taliban'a bırakmıştır.

ABD, Afgan halkı ile Taliban'a karşı sadece stratejik değil taktiksel avantaj sağlamak için anlatılar ile bağ geliştirmeye çalışmıştır. ABD, Taliban'a karşı bir köyden istihbarat almaktan, Afgan halkıdan lojistik destek istemeye ve kimi zaman da Afganlıları merkezi yönetime ve uygulamalarına destek vermeye ikna için stratejik iletişim çatısında anlatıları ihtiyaç duymuştur. Bu süreç içerisinde de daima Taliban'ın anlatısı ile mücadele etmek durumunda kalmıştır. Taliban'ın dilsel, kültürel ve dinsel avantajları ile rekabet etmek ABD için zorlayıcı olmuştur. Özellikle, sivil kayıplardan ve kültürel ya da dini hassasiyetlere yeteri kadar önem verilmemesinden ötürü bozulan eylem-söylem bütünlüğü anlatı ile kazanılmak istenilen stratejik avantajı bertaraf etmiştir. NATO'nun çok uluslu ve askeri bürokrasisi de anlatısının ihtiyacı olan ortak bir dil geliştirilmesini zorlaştırmıştır.

\section{Taliban'ın Stratejik Anlatısı}

ABD'nin anlatısına karşı Taliban kendi anlatısı ile Afganistan savaşında stratejik avantaj elde etmek istemiştir. 2010 yılında Afganistan'da 1000 erkek üzerinde Uluslararası Güvenlik ve Kalkınma Konseyi'nin (International Council on Security and Development-ICOS) tarafından yapılan çalışmanın sonuçları Afganistan savaşında anlatının yerinin anlaşılmasına yönelik değerli veriler sunmaktadır. Çalışma sonucunda, Helmand ve Kandahar'da ankete katılan 1000 Afgan erkeğinin yüzde 92'sinin 2001'de ABD'de gerçekleşen ve 9/11 olarak bilinen saldırıları duymadıkları ortaya çıkmıştır (ICOS, 2010). Diğer bir ifade ile, Afganistan'da savaş 10. yılına girerken Afganistan'da yaşayan farklı bölgelerden ve etnik gruplardan insanların neredeyse tamamı ABD'nin neden Afganistan'da bulunduğuna dair halen fikir sahibi değillerdi. Taliban'ın ise bu durumu kendi avantajına çevirmesi ise son derece kolay olmuştur.

Taliban'ın anlatısının güç aldığı en önemli kaynak Afganistan'ın tarihi, kültürü ve dini yapısı olmuştur. Johnson ve Steele'ye göre (2013: 74) Taliban'ın anlatısını oluşturan bileşenler basit ama birbiri ile ilişkili parçalardan oluşmuştur. Johnson ve Steele, öncelikle Taliban anlatısında kendilerinin zaferinin kaçınılmaz olacağını ve Taliban'ın Afganistan'ın kontrolünü yakında yeniden elde edeceğini vurguladıklarına dikkate çekmiştir. Taliban, bu vurgusunu İslam'ın yenilmezliği üzerine ve Taliban'ın Allah ve ülke için fedakarlıklar yapmaya istekli olmasına bağlamıştır. Nitekim anlatı ile çizilen çerçevede Afganların uzun ve şerefli bir geçmişleri vardır ve Afganlılar dinlerini ve geleneklerini yok etmeye çalışan yabancı işgalciler ile Afganistan'daki kukla yönetime karşı çıkacaklardır. Afgan halkı, daha önce İngilizlere ve Ruslara karşı verdikleri mücadeleyi şimdi ABD ve NATO'ya karşı vermektedir. Taliban'a göre Afganistan'a gelen yabancılar İslami kurallara göre halkın yaşamasına da engel olmaktadır, dahası İslam dinine en büyük tehdidi oluşturarak Afganistan'ı Hristiyanlaştırmak istemektedir. Johnson ve Steele, bu temelden yola çıkarak Taliban'ın anlatıları ile hitap ettiği gruplar arasındaki ilişkiyi de kurgulamıştır. Onlara göre Taliban, anlatılarının çoğunu Afgan halkının paylaştığı üç temel sosyal kimliğe aynı anda hitap etmek için hazırlamıştır. Bu kimlikler dini yani İslami, kültürel ve politik kimliklerdir. İslami kimliğe yönelik anlatı bölgesel ve uluslararası kamuoyuna hitap edebilecek güçtedir. Bunun yanı sıra Taliban toplumda aşırıcı, muhafazakâr ya da 11ımlı olsun ortak dini kimliği paylaşan herkesi içine alacak bir anlatı geliştirmiştir. Öte yandan Taliban, kültürel kimliklere yönelik bölgesel olarak daha dar bir alanda farklı etnik gruplara hitap edebilecek anlatıları kullanmıştır. Ulusalcıları ve İslamcıları içine alan politik kimliklerle de ülke genelinde tüm grupları içine almaya çalışmıştır. Yabancıların işgali, bağımsızlık, adalet ve mağduriyet üç kimliği de içine alırken, gurur ve onur ile Peştunluk kültürel ve politik kimliklere yönelik anlatıların temelinde yer almıştır (2013: 75). 
Bu çerçevede Taliban'ın birbiri ile de ilişki içinde olan 'kurtuluş için Taliban', 'yabancılar dışarı' ve 'dinimizi elimizden alacaklar' şeklinde üç temel anlatı sistemi geliştirdiğini söylemek mümkündür.

Anlatının kendisi kadar anlatının aktarılması ve yayılması amacıyla kullanılan kanallar da son derece önemlidir. Afganistan'daki kırsal nüfusun modern medya araçlarına ulaşma imkanlarının kısıtlı olduğunu fark eden Taliban, öncelikle geleneksel, düşük teknolojili ve uygun maliyetli anlatım yöntemleri kullanmıştır. ABD'nin anlatıları yüz yüze yayma konusundaki dezavantajına karşın Taliban etnik kimlik, kültür ve dil gibi avantajları kullanarak anlatılarını çok kolay yayabilmiş ve daha da önemlisi benimsetebilme avantajına sahip olmuştur. Taliban, bir mesajı iletmek için iyi bilinen Afgan masallarını ve taranas adı verilen yerel şiir ve ilahileri kullanmıştır. Bu yolla, Taliban, Afganistan'daki insanların kolektif anılara ulaşarak insanların duygularına hitap etmiştir. Bunların yanı sıra özellikle gece mektupları (shabnamah) Taliban'ın anlatısında güçlü bir yere sahip olmuştur. Tarihsel olarak Afganistan'da geçmişte de çok kullanılmış olan gece mektupları genelde bir sayfa uzunluğunda olmakta ve belirli bir konuda Taliban'ın talimatlarını içermekteydi. Mektuplar, Taliban'ın Afganistan' daki kukla hükümet ve onların işgalci yabancı müttefikleri ile mücadelesine insanları çağırmak ya da yabancı işgalcileri İslami yıkmaya çalışan yabancılar olarak anlatmak için yazılmaktaydı (Johnson, 2017: 5355). Mektuplar anlayış̧ı bir tonda olabildiği gibi tehditkâr bir tonda olabilmekteydi. Örneğin çocukların okula gönderilmeye devam edilmesi ya da Amerikalılara yardım edilmesi durumunda ölümle mektubu alan köye ya da kişi tehdit edilmekteydi (Rabiroff, 2010). Mektuplar, özel olarak insanlara ulaştırıldığından 'sizi biliyoruz ve yakınınızdayız' mesajı da taşıdığından etkisi yüksek olmaktaydı. Dolayısıyla gelenekselleşen bu yöntem ile verilmek istenilen mesaj hızı bir şekilde yayılabiliyordu.

Taliban'ın anlatısını yaymak için kullandığı diğer bir araç ise layiha (layeha) olarak bilinen 'davranış kuralları' rehberleriydi. Taliban lider kadrosu tarafından, Taliban'ın mücahitleri ve destekçileri için 2006, 2009 ve 2010 yıllarında layihalar yayımlamıştır. Layihalar, Afgan Taliban'ın hedefleri, stratejileri ve Taliban liderliğinin ruhu / bakış açısı hakkında önemli bilgiler sunmaktadır (Johnson \& DuPee, 2012: 77). 2006 yılında yayımlanan ilk layihada mücahitler için 30 kuraldan bahsedilmiştir. Mücahitlerin, günlük yaşantıları, komutanları ve grubun geri kalanı ile ilişkileri gibi farklı konularda kurallar konulmuştur (Adamec, 2012: 469-47). 2009 yılında yayımlanan ikinci layihada ise Taliban'ın daha sistemli bir yaklaşım geliştirdiği görülmektedir. Güvenlik, tutsaklar, ajanlar, düşmanın lojistik ve inşaat faaliyetleri, ele geçirilen mühimmatlar, örgüt yapısı, mücahidin özel meseleleri, eğitim-öğretim, yerel personel konuları, yasaklanan hususlar ve tavsiyeler başlıkları altında 67 kural ortaya konulmuştur. Bu bölümde, cihadın Müslümanlar için en kutsal görev olduğundan bahsedilerek, bu kutsal görevin gerek bu dünyada gerekse ölümden sonraki hayatta pek çok ödülü olduğundan ifade edilmektedir (Frontline [web], 2009). 2010 y1lında yayımlanan lahiyanın kurallar bölümünde aynı sistemli yaklaşım sürdürülmüş ve kurallara ilişkin sınırlı düzenlemeler yapılmışıı (Afghanistan Analysts Network [web], 2010). Yayımlanan üç layihayı inceleyen ve karşılaştıran Johnson ve DuPee de söz konusu layihaların Taliban'ın hedeflerine ilişkin önemli bilgiler içerdiğini vurgular. Çalışmaları sonucunda Johnson ve DuPee, Taliban'ın yerel halkın kalplerini kazanıp akıllarına girerek, kamu desteği elde etmek, çatışma sahasında etkinliğini sürdürebilmek için yeterli sayıda savaşçının sürekliliğini sağlamak, Afganistan'ın mevcut hükümetinin yerine geçebilecek kapasitede olduğu algısını yaratmak, komuta-kontrol yapısının bütünlüğünü tesis etmek, iletişim ile ilgili sorunları gidermek, en tepedeki liderin, diğer bölgelerdeki savaşçıları ve lideri koordine etmesinin önündeki zorlukları kaldırmak başta olmak üzere daha operasyonel ya da taktik seviyede hedefler ortaya koyduğunu ifade eder (2012: 77-91). Layihaların öncelikli hedef kitlesini mücahitler ve destekçileri oluşturmasına karşın uluslararası kamuoyu ve Afgan halkı da layihaların hedef grupları içerisinde yer alarak Taliban'ın anlatısının daha geniş bir alanda karşılık bulmasına imkân sağlamıştı.

Taliban, anlatısını yayarken geleneksel yöntemlere ağırlık vermekle birlikte teknoloji de Taliban tarafından anlatının yayılmasında kullanılan önemli bir araç olmuştur. Radyo, Taliban için en önemli kitle iletişim aracı olarak kullanılmıştır. Taliban, Afganistan'da iktidar olduğu dönemde Şeriat Radyosu 
(Shariah Radio) adıyla yayın yaparken, ABD'nin radyo istasyonunu 2001'de bombalamasıla yayınları sonlanmıştır. Ancak 2005 yılından itibaren radyo yayını yapma imkanına tekrar kavuşan Taliban Şeriat'ın Sesi Radyosu (Voice of Shariah Radio) ile yasadışı yollarla radyo yayınlara devam etmiştir (Crew, 2009: 245). Taliban, 2005 yılının ortasında Al Emarah adlı bir web sitesini kurmuş ve siteyi 2019 yılının ilk çeyreğine kadar işlevsel tutmayı başarmıştır. Ayrıca yeni medya araçlarını son derece etkin bir şekilde kullanmıştır. Bugün halen Facebook'da Taliban'ın aktif olan platformları vardır. Ayrıca, Twitter ve YouTube'da Taliban'ın etkin olduğu sosyal medya platformları arasındadır. Facebook, Twitter ve YouTube gerekli hallerde Taliban'ın hesaplarını kapatmalarına karşın, Taliban hızla yedek hesaplara geçiş yapılmaktadır.

Dorronsoro, Taliban'nın anlatısında Afgan hükümetinin yolsuzluklarına ve halk için temel hizmetleri sağlayamadığına da yer verdiğini belirtmektedir (2009). Bu hususlar, anlatısının en güçlü yanları olmamakla birlikte Taliban'ın özellikle Afgan hükümeti karşıtı anlatısının parçalarıdır. BM Uyuşturucu ve Suç Ofisi (UN Office on Drugs and Crime-UNODC) tarafından 2009 ve 2012 yillarında yapılan ve Afganistan'da yolsuzluk eğilimlerini gösteren çalışma Afganistan'da rüşvetin yetişkinler tarafından kamuda işlerini halletmek amacıyla ne kadar yaygın olduğunu ortaya koymuştur. Araştırma sonucunda 2009 yılında Afganistan'da rüşveti kamuda işlerini halletmek amaciyla kullanan yetişkinlerin oranı \%58 iken, bu oranın 2012 yılında \%50'ye düşmüştür. Ancak, araştırma sonuçları 2012 yılında rüşvet verenlerin oranında genel bir düşüş olduğunu göstermekle birlikte rüşvetin ödenme s1klığında bir yükseliş olduğu sonucunu da ortaya koymuştur. Buna göre, Afganistan'da yetişkin biri 2009 yılında y1lda ortalama 4.7 defa rüşvet verirken, bu oran 2012 y1lında 5.6'ya yükselmiştir (UNODC, 2013). UNODC tarafindan Afganistan'daki yolsuzluğa ve patronaj ağına ilişkin yürütülen bu araştırma Taliban'ın kendine meşruluk ararken nasıl bir zeminde durduğunu göstermesi açısından önemlidir. Cordesman'a göre Afganistan'da yolsuzluk ve beraberinde getirdiği patronaj sistemi nedeniyle hükümet ile toplum arasındaki bağlar güçlü değildir. Dolayısıyla merkezi hükümet ile bölgesel ve yerel bağlar zayiftır ([web], 2013: 29).

Taliban, anlatısının güçlü yanları ile elde ettiği avantaja rağmen sahada yerel halka karşı acımasız, şiddet yanlısı davranışları ile dezavantajlı olduğu bir pozisyon yaratmıştır. Afgan halkına çeşitli gerekçelerle saldırarak sivillerin ölümlerine ya da yaralanmalarına neden olmuştur. Nitekim, Taliban 2010 yılında yayınladığı layihada, Taliban'ın kaçırılma olaylarına karışmasını, haraç alınmasını, sivillerin yaralanmasını, rüşvet alınmasını ve öğrencilere saldırılar konusundaki tepkileri dikkate alarak üyelere uyarılarda bulunulmuştur (Afghanistan Analysts Network [web], 2010). Örgüt yapısındaki zayıflıklar üst ve orta düzey liderler arasındaki etkileşimin azlığı anlatıdaki tutarlılığı ortadan kaldıran ve dezavantaj yaratan diğer bir unsur olmuştur (Johnson, 2017: 35). Özellikle alt ve orta kademedeki üyelerin örgüt içerisinde yükselmek ve popülerlik kazanmak için kendilerini kahraman olarak göstermeye odaklanmaları Taliban'ın anlatısına uygun davranmamalarına dolayısıyla da anlatının amacından uzaklaşılmasına neden olmuştur. Diğer bir ifade ile Taliban'ın sivil halka karşı uyguladığı şiddet, lider kadronun tutarsızlıkları ve kahramanlık gösterileri anlatının gücünü aldığı eylem-söylem bütünlüğüne zarar vermiş ve anlatının gücünü zayıflatmıştır.

Taliban'ın Afganistan'ın tarihine, kültürüne ve İslam'a dayalı olarak geliştirdiği anlatılar son derece basit ve anlaşılabilir olmuştur. Taliban'ın anlatısına stratejik avantaj sağlayan en önemli husus da bu olmuştur. Taliban'ın dil, din ve kültür üzerinden sahip olduğu avantajların yanı sıra yerel halkın arasına karışabilmesi ve kimi zaman onlarla aynı yaşam alanlarını paylaşabilmesi anlatısının yayılmasında ve anlaşılmasına avantaj sağlamıştır. Sözel kültürün geliştiği bir toplumsal yapıdaki şiir, masal ve ilahi gibi araçları bile sahip olduğu bu avantaj ile etkin bir şekilde kullanmıştır. Öte yandan, sivil halka yönelik şiddet Taliban'ın anlatısı ile kazanmaya çalıştığı Afgan halkının ona karşı tepki geliştirmesine neden olmuştur. Eylem-söylem bütünlüğünün sağlanamamasından kaynaklı bir sorun oluşturmuş ve anlatıda stratejik bir dezavantaj yaratmıştır. 


\section{Sonuç}

Savaş anlatıları aracılığı ile uluslararası, ulusal ve bölgesel düzeyde kamuoylarına savaşları anlamaları ve anlamlandırmaları için bir açıklama çerçeveleri oluşturulur. Bu iktidarlara savaş zamanı yönettikleri insanların desteklerini alabilmeleri için gerekli yolu açar. Aynı zamanda operasyon sahasında yerel halktan aldıkları destekle düşman unsurlara karşı istihbarat, lojistik ya da harekât konularında operasyonel ve taktik avantajlar sağlar. Bu yönüyle de anlatılar uluslararası, ulusal ve bölgesel düzeyde olduğu gibi uzun, orta ve kısa vadede etkili araçlardır. Anlatıların günümüz savaşlarındaki stratejik değerinin öneminin arttı̆̆ını, diğer bir deyişle stratejik anlatının savaşlardaki rolünün dikkate alınmasının kaçınılmaz olduğu görülmektedir.

Anlatının savaşlardaki rolünün en açık gözlemlenebileceği örneklerden biri de Afganistan savaşıdır. Afganistan savaşı, her zaman bir anlatı savaşı olmuş ve ABD ile Taliban'ın anlatıları birbirlerinin karşı anlatıları olarak her zaman rakip olmuşlardır. Her iki taraf anlatılar aracılığı ile Afgan halkının desteğini kazanmayı amaçlamışlardır. Çünkü savaşlarda halkın desteğini almak stratejik bir avantaj elde etmek anlamına gelmektedir. Bununla birlikte ABD ve Taliban anlatılarını güçlendiren ve zayıflatan birtakım avantajlara ve dezavantajlara sahip olmuşlardır. ABD, ileri teknolojisine, 11 Eylül saldırılarının sağladığı meşruiyete rağmen kendi kamuoyunda ve uluslararası kamuoyunda yarattığı etkiye benzer bir etkiyi anlatılar yoluyla Afgan halkı üzerinde yaratamamıştır. ABD, Taliban'ın dilsel, kültürel ve dinsel avantajları ile rekabet ederken zorlanmıştır. Özellikle, sivil kayıplardan ve dini hassasiyetlere yeteri kadar önem verilmemesinden ötürü anlatıların gücünü aldığı eylem-söylem bütünlüğü bozulmuştur. Öte yandan, Taliban'ın Afganistan'ın tarihine, kültürüne ve İslam'a dayalı olarak geliştirdiği son derece basit ve anlaşılabilir anlatılar en büyük avantajı olmuştur. Taliban'ın halkın arasına karışabilmesi paylaşabilmesi anlatısının yayılmasında ve anlaşılmasına avantaj sağlarken, sivil halka yönelik şiddeti Afgan halkının Taliban’a karşı tepki geliştirmesine neden olmuştur.

\section{KAYNAKÇA}

Adamec, L. W. (2012). Historical Dictionary of Afghanistan. Scarecrow Press: Maryland.

Afghanistan Analysts Network Page. (2010). Translated text of the 2010 Version of the Taleban Code of Conduct. Erişim http://www.afghanistan-analysts.org/wpcontent/uploads/downloads/2012/10/Appendix_1_Code_in_English.pdf

Bilgin, K.R. (2018). New Aspect of the Relationship between War and Strategy: Strategic Narrative. Humanities and Social Sciences Review, 08 (01), 239-244.

Burget, F.A. (2013). Afganistan'da 2014 Beklenirken: Taliban Örgütü ve Yeni Bir Siyasal Sürece Doğru Yeni Gruplaşmalar. Ortadoğu Analiz, 5, (52), 95-103.

C. Tilly (1985). War Making and State making as Organized Crime. In P. Evans \& D. Rueschemeyer \& T. Skocpol (Eds.), From Bringing the State Back (pp. 169-191). Cambridge University Press: Cambridge.

Cordesman, A. (2013). The Challenges of Leadership and Governance. A Report of the CSIS Burke Chair in Strategy, Center for Strategic and International Studies. Erişim http://csis.org/files/publication/130506_Cordesman_AfghanWar2013_VolumeI_Web.pdf

Corman, S. R. (2011). Understanding the Role of Narrative in Extremist Strategic Communication. In L.Fenstermacher \& T. Leventhal (Eds.), Countering Violent Extremism: Scientific Methods and Strategies (pp. 36-43). Air Force Research Labrotary: Dayton OH.

Crews, R. D. (2009). Moderate Taliban. In R.D. Crews \& A.Tarzi (Eds.). The Taliban and the Crisis of Afghanistan (pp. 238-273). Harvard University Press: London. 
Dimitriu, G. \& Graff, B. (2016). Fighting the War at Home: Strategic Narratives, Elite Responsiveness, and the Dutch Mission in Afghanistan, 2006-2010. Foreign Policy Analysis, 12, 2-23.

Dimitriu, G. R. (2012). Winning the Story War: Strategic Communication and the Conflict in Afghanistan. Public Relations Review, 38 (2), 195-207.

Dorronsoro, G. (2009). The Taliban's Winning Strategy in Afghanistan. Carnegie Endowment. Erişim https://carnegieendowment.org/files/taliban_winning_strategy.pdf

Freedman, L. (2006) The Transformation of Strategic Affairs. Routledge: London.

Frontline Page. (2009). Taliban 2009 Rules and Regulations Booklet. Erişim http://wwwtc.pbs.org/wgbh/pages/frontline/obamaswar/etc/mullahomar.pdf, 2009

Graaf, B. \& Dimitriu, G. \& Ringsmose, J. (2015). Shaping Societies for War: Strategic Narratives and Public Opinion. In B. Graaf \& G. Dimitriu \& J. Ringsmose (Eds.), Strategic Narratives, Public Opinion and War: Winning Domestic Support for the Afghan War, (pp. 3-15). Routledge: Oxon.

Güler, R. (2018). Stratejik İletişim: Güvenlik Odaklı Yönetimi Paradigmaları. Karkum: Ankara.

Johnson, T. (2017). Taliban Narratives: The Use and Power of Stories in the Afghanistan Conflict. Oxford Press: Oxford.

Johnson, T. \& Steele, K. L. (2013). The Taliban Narrative: Understanding the Group's Messages, Actions and Clues to Their Endgame. In S. R Corman (Ed.), Narrating the Exit from Afghanistan (pp. 71-98), Center for Strategic Communication: Tempe, Arizona.

Johnson, T.H. \& DuPee, M. C. (2012). Analysing the New Taliban Code of Conduct (Layeha): An Assessment of Changing Perspectives and Strategies of the Afghan Taliban. Central Asian Survey. 31 (1), 77-91.

Kilcullen, D. (2007). Counter-Insurgency in Iraq, Theory and Practice. Erişim www.smallwarsjournal.com

ICOS (2010). Afghanistan Transition: Missing Variables Erişim http://www.icosgroup.net/

Ryan, M. (2004). Framing the War Against Terrorism US Newspaper Editorials and Military Action in Afghanistan. The International Journal for Communication Studies, 66(5): 363-382.

Miskimmon, A. \& O'Loughlin, B. \& Roselle, L. (2013). Strategic Narratives: Communication Power and the New World Order. Routledge: New York.

Nissen, T. E. (2014). Strategizing NATO's Narrative. In L. Odgaard (Ed.), Strategy in NATO: Preparing for an Imperfect World, (pp.157-172). New York: Palgrave.

Rabiroff, J. (2010). Chilling 'Night Letters' from Taliban Intimidate Afghans. Erişim https://www.stripes.com/news/chilling-night-letters-from-taliban-intimidate-afghans-1.127043

Ringsmose, J. \& Børgesen, B. (2011). Shaping Public Attitudes toward the Deployment of Military Power: NATO, Afghanistan and the Use of Strategic Narratives. European Security, 20, 505528.

Scheffer, J. H. (2015). Framing the War in Afghanistan: An Introductory Note. In B. Graaf \& G. Dimitriu \& J. Ringsmose (Eds.), Strategic Narratives, Public Opinion and War: Winning Domestic Support for the Afghan War (pp. XXIII-XVII). Routledge: Oxon.

Shaikh, S. A. \& Payne, R. D. (2014). Narrative in the Operations Process. In M.A. Finlayson, J.C.Meister \& E.G.Bruneau (Eds.), 5th Workshop on Computational Models of Narrative (pp.28), OASICS: Canada. 
Tatham, S. (2009). Strategic Communication: A Primer. Erişim http://www.carlisle.army.mil/dime/documents/DAUKARAG08(28)Strategic\%20Communicati on.pdf.

UNODC (2012). Corruption in Afghanistan: Recent Patterns and Trends. Erișim http://www.unodc.org/documents/frontpage/Corruption_in_Afghanistan_FINAL.pdf

USACAC (2006). FM 3-24 Counterinsurgecy Field Manual. Erişim https://usacac.army.mil/cac2/repository/materials/coin-fm3-24.pdf

Vlahos, M. (2006). The Long War: A Self-Fulfilling Prophecy of Protracted Conflict and Defeat. National Institute Online. Erişim www.nationalinterest.org/PrinterFriendly.aspx?id=11982.

Zahara, R.S. (2010). Battles to Bridges. Palgrave: New York.

Wendt, A. (1992). Anarchy is What States Make of it: The Social Construction of Power Politics. International Organization, 46 (2), 391-425.

Whitehouse (2019). George W. Bush Archives. Erişim https://georgewbushwhitehouse.archives.gov/news/briefings/index.html\#y2001

Williston J. A. (2015). Toward a Strategic Communication Plan for the Afghanistan Humanitarian Intervention Mission, University of Ottawa Master Thesis, Erişim https://ruor.uottawa.ca/bitstream/10393/32244/1/Williston_John_2015_Thesis.pdf 